\title{
The first fossil salmonfly (Insecta: Plecoptera: Pteronarcyidae), back to the Middle Jurassic
}

\author{
Yingying Cui ${ }^{1,2}$, Olivier Béthoux ${ }^{1}$, Boris Kondratieff ${ }^{3}$, Chungkun Shih $^{2,4}$ and Dong Ren ${ }^{2 *}$
}

\begin{abstract}
Background: The fossil record of Plecoptera (stoneflies) is considered relatively complete, with stem-groups of each of the three major lineages, viz. Antarctoperlaria, Euholognatha and Systellognatha (and some of their families) represented in the Mesozoic. However, the family Pteronarcyidae (the salmonflies; including two genera, Pteronarcys and Pteronarcella) has no fossil record to date, and the family has been suggested to have diverged recently.

Results: In this paper, we report on a set of specimens belonging to a new fossil species of stonefly, discovered from the Middle Jurassic Daohugou locality (China). Our comparative analysis of wing venation and body characters demonstrates that the new species belongs to the Pteronarcyidae, and is more closely related to Pteronarcys than to Pteronarcella. However, it differs from all known species of the former genus. It is therefore assigned to a new genus and named Pteroliriope sinitshenkovae gen. et sp. nov. under the traditional nomenclatural procedure. The cladotypic nomenclatural procedure is also employed, with the resulting combination Pteroliriope nec Pteronarcys sinitshenkovae sp. nov.

Conclusions: The first discovery of a fossil member of the Pteronarcyidae demonstrates that the corresponding lineage is not a very recent offshoot but was already present ca. 165 million years ago. This discovery concurs with the view that divergence of most stonefly families took place very early, probably in the Triassic, or even in the Permian. This contribution demonstrates the need for (re-)investigations of the systematics of fossil stoneflies to refine divergence date estimates for Plecoptera lineages.
\end{abstract}

\section{Background}

The insect order Plecoptera (stoneflies) diverged as early as in the early Late Carboniferous [1], and stem-relatives of most of its constituent families have been recovered from Mesozoic strata [2-9]. However the Pteronarcyidae (salmonflies; including two extant genera, Pteronarcys Newman, 1838 [10] and Pteronarcella Banks, 1900 [11]), a prominent family as far as the size of individuals is concerned, has never been recovered in the fossil record. As a consequence it is generally assumed that the family diverged very recently (Cenozoic [2, 4]).

In this paper, we report on a large set of specimens belonging to a new fossil species of stonefly, unearthed from the Middle Jurassic Daohugou locality (China). Our comparative analysis of wing venation and body

* Correspondence: rendong@mail.cnu.edu.cn

${ }^{2}$ College of Life Sciences, Capital Normal University, Beijing 100048, China

Full list of author information is available at the end of the article characters unambiguously demonstrates that the new species is a Pteronarcyidae. Its affinities within this family are elucidated and the implications of this new occurrence on divergence date estimates for stonefly lineages are addressed.

\section{Results}

In order to assess the affinities of a newly discovered fossil species, we conducted a comparative analysis of characters of the external morphology. Firstly we complemented the available data on the wing venation of Pteronarcella badia (Hagen 1874) [12], a close relative of the new species. Then we address systematics aspects above the species level (divided into the traditional and the cladotypic approaches), followed by species-level aspects. 


\section{Wing venation variability in Pteronarcella badia}

During our survey, we discovered that there was a lack of data on the wing venation of Pteronarcella badia, a critical species for comparison. An incomplete view of a forewing is available in Needham \& Claassen (1925) [13] (Fig. 11), and a fore- and a hind wing are illustrated by Nelson \& Hanson 1971 [14]: (Figs. 23-26). We investigated nine macropterous specimens (three males, six females). The typical morphology of the species is represented by Fig. 1a-d for males and Fig. 1e-h for females. In both fore- and hind wing, it involves a 3- or 4branched RP, a 2-branched M (i.e. both MA and MP simple), a simple $\mathrm{CuA}$, and no cross-veins in the area between $\mathrm{R} / \mathrm{RP}$ and $\mathrm{M}$ basal to the first fork of $\mathrm{M}$. In forewings, the rp-ma cross-vein is long, and AA2 has 2-3 branches.

Unusual morphologies were documented: one individual exhibited a short rp-ma cross-vein in both forewings (Fig. 1i.1,2); one individual exhibited a $\mathrm{CuA}$ forked distally in both forewings (only left forewing represented on Fig. 1i); one individual exhibited a long stem of AA2 (Fig. 1j); another one, not illustrated, has also such a distal fork in one of the forewings (Fig. 1k.1,2); one individual has $\mathrm{CuP}$ fused for some distance with $\mathrm{CuA}$
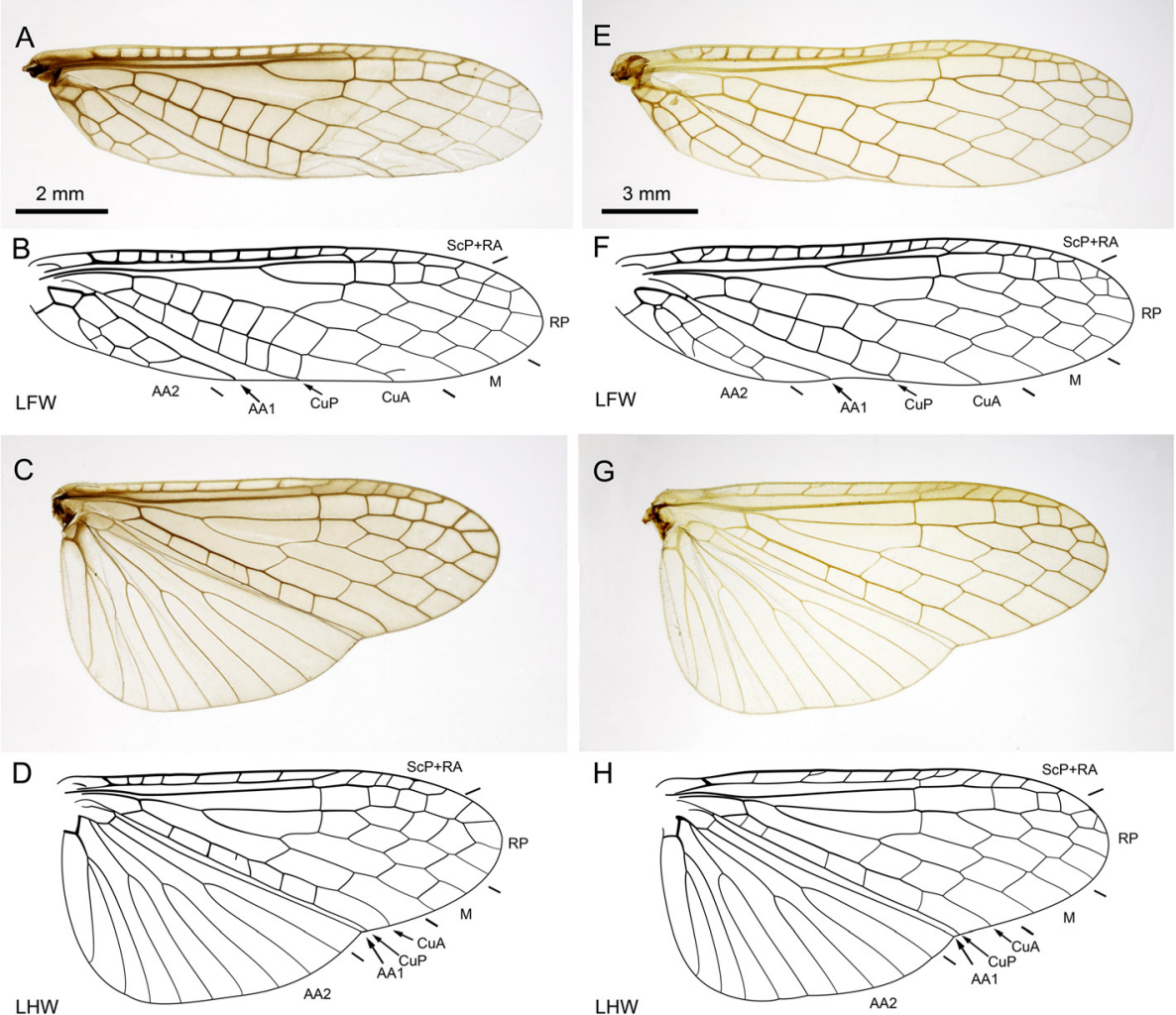

$\mathrm{H}$
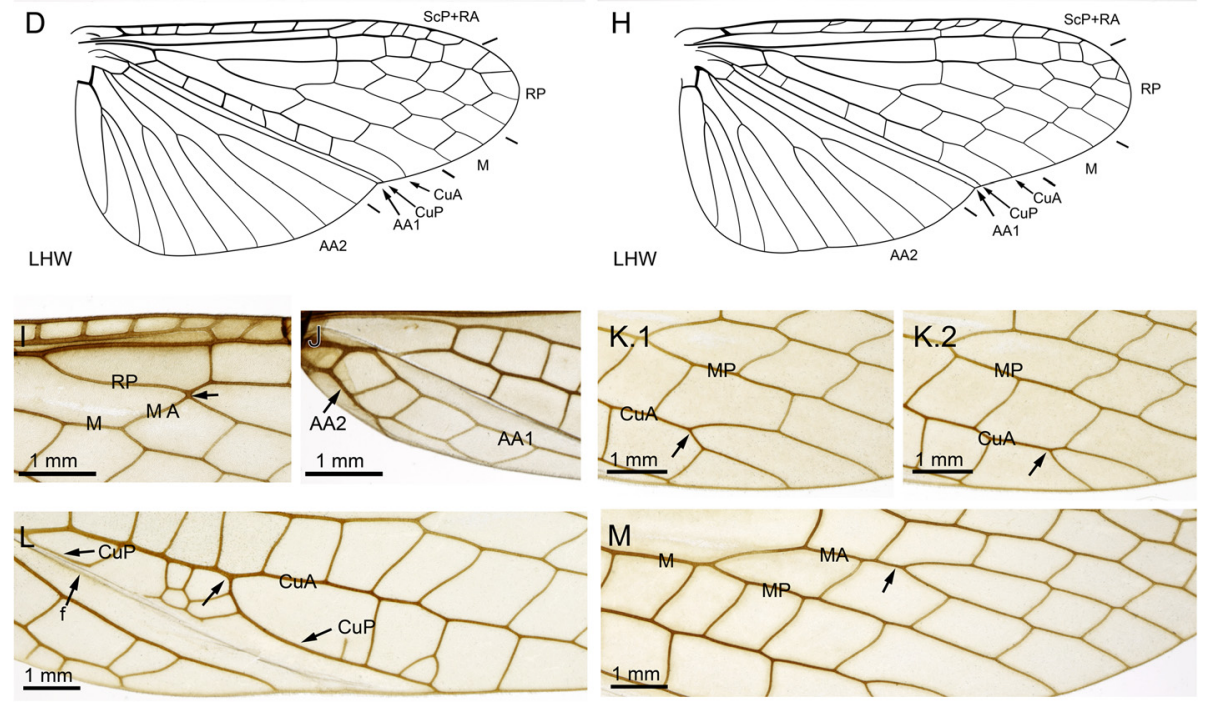

Fig. 1 Wing venation of Pteronarcella badia (Hagen, 1874). a-d, Specimen MNHN.EP654 (male), photographs and drawings of left forewing and left hind wing; (e-h), Specimen MNHN.EP657 (female), photographs and drawings of left forewing and left hind wing; (i-m), photos of detail of forewing venation variability; (i), Specimen MNHN.EP655 (male), left forewing; (j), Specimen MNHN.EP656 (male), left forewing; (k).1-K.2, Specimen MNHN.EP658 (female), right and left forewing respectively; (I), Specimen MNHN.EP661 (female), left forewing; (m), Specimen MNHN.EP662 (female), right forewing 
(Fig. 11); one individual has a branched MA (Fig. 1m); one unusual individual has an incomplete cross-vein in the area between R/RP and $M$ basal to the fork of $\mathrm{M}$ in the right forewing, and $\mathrm{MP}$ fused with $\mathrm{CuA}$ in the right hind wing, among other aspects (not illustrated).

\section{Systematics above species level Traditional nomenclature}

Plecoptera Burmeister, 1839
Systellognatha Zwick, 2000

Pteronarcyidae Newman, 1853

Pteroliriope Cui, Béthoux, Kondratieff, Shih \& Ren, gen. nov.

(urn:Isid:zoobank.org:act:514D4664-70D2-4A89-AFA1B9B9423052D8)

Type species: Pteroliriope sinitshenkovae gen. et sp. nov. (Figs. 2, 3, 4, 5, 6, 7 and 9A.2)

Diagnosis: By monotypy, that of its constituent species.
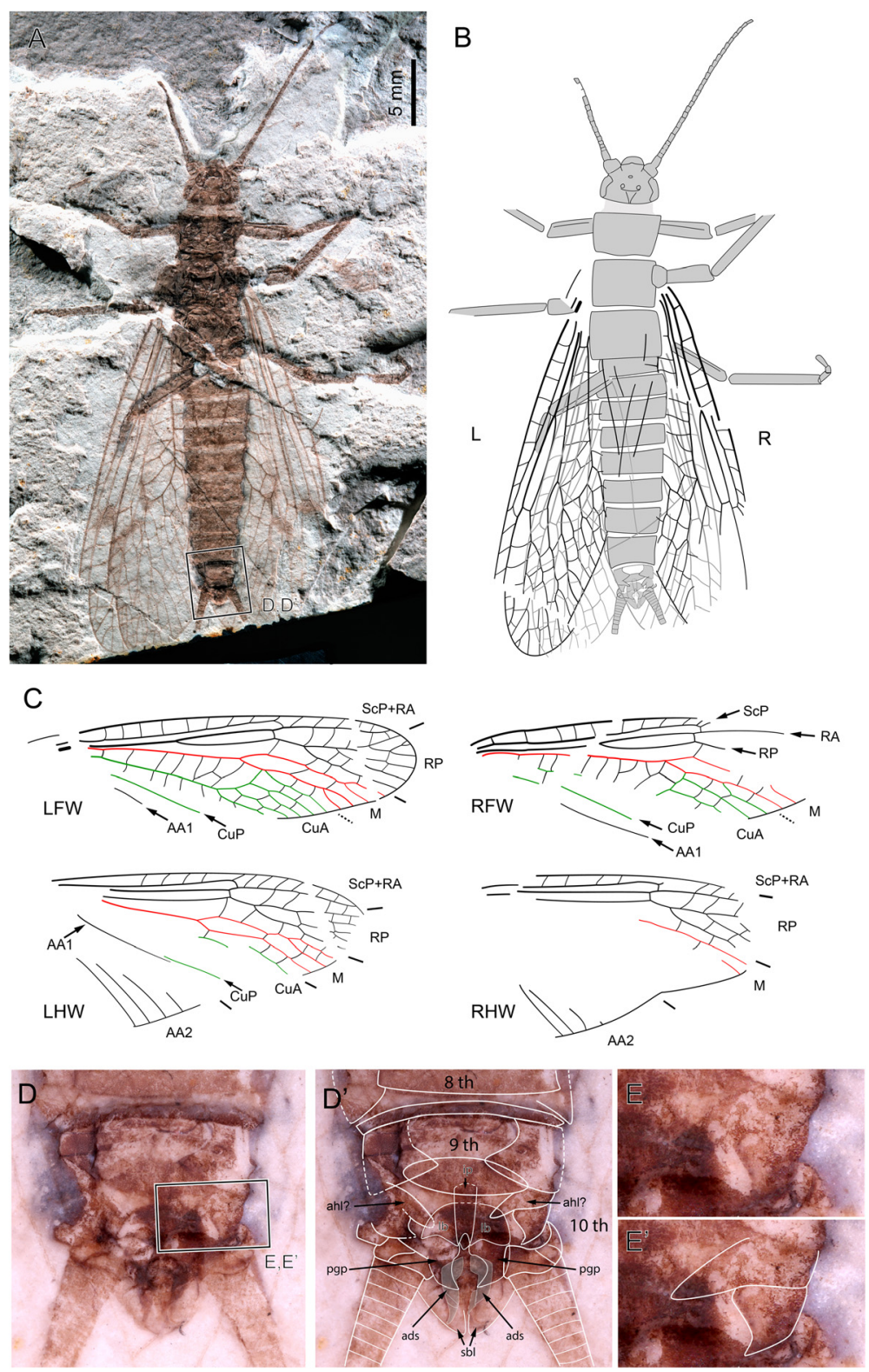

Fig. 2 Pteroliriope sinitshenkovae tax. et sp. nov. (Middle Jurassic; Daohugou, China), specimen CNU-PLE-NN-2015001, holotype; (a), Photograph (composition of positive and negative imprints); (b-c), Drawings; (d-d'), Detail photograph (composition of positive and negative imprints, both dry and under ethanol, reversed) of posterior part of male postabdomen, without (d) and with (d') interpretation, as located on (a); (e-e'), Detail photograph (composition of positive and negative imprints, both dry and under ethanol, reversed) of hemitergal lobe, without (e) and with (e') interpretation, as located on (d) 

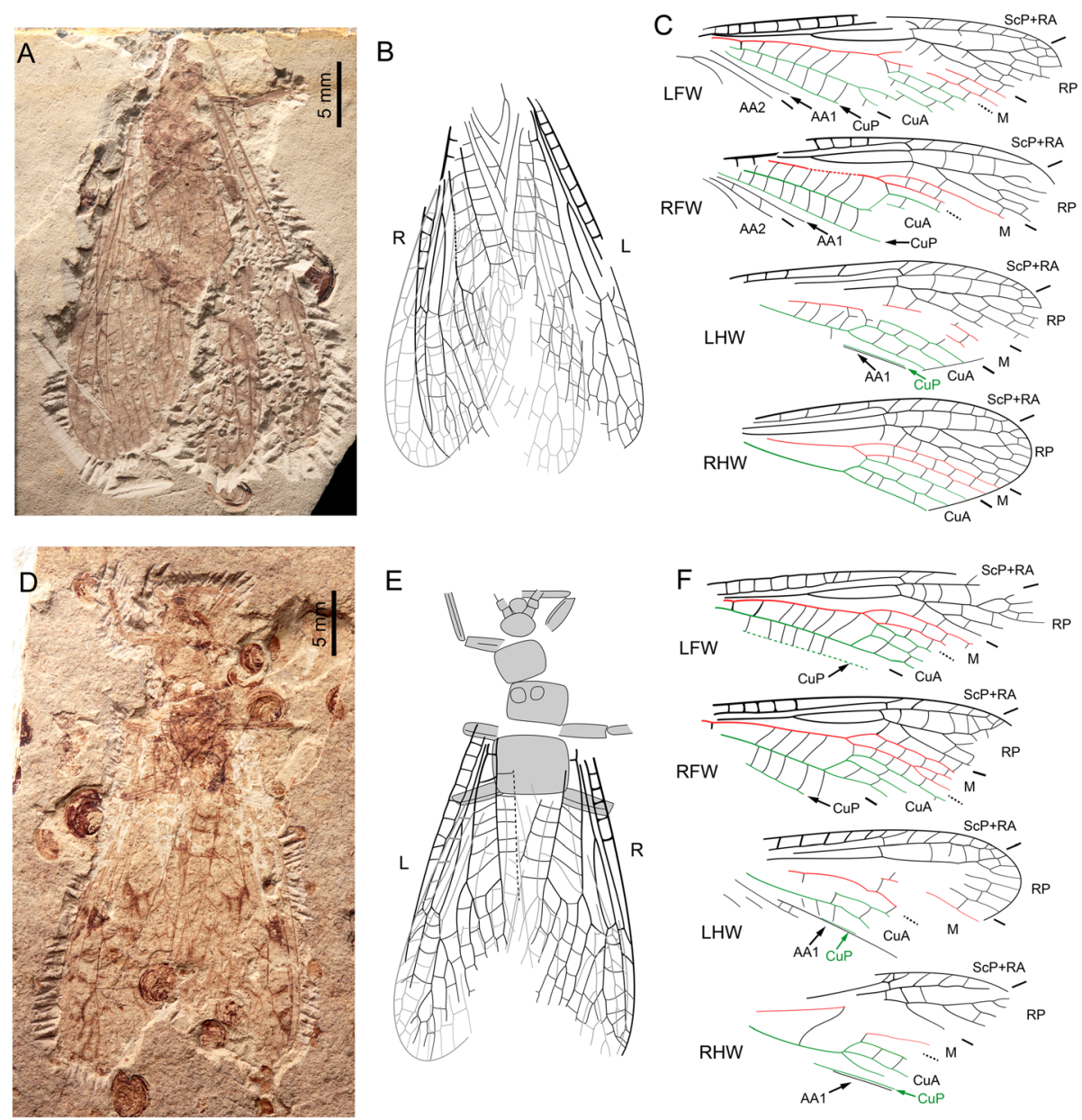

Fig. 3 Pteroliriope sinitshenkovae tax. et sp. nov. (Middle Jurassic; Daohugou, China). a-c, Specimen CNU-PLE-NN-2013001; (a), Photograph (negative imprint); (b-c), Drawings; (d-f), Specimen CNU-PLE-NN-2013004; (d), Photograph (positive imprint); (e-f), Drawings

Etymology: Based on 'Pteron' ('wing' in ancient Greek), and 'Liriope', a nymph considered the mother of Narcissus in Greek mythology (the name of a related genus, Pteronarcys, is based on 'Narcissus').

Composition: Pteroliriope sinitshenkovae gen. et sp. nov.

Discussion: The type-species of the proposed new genus exhibits a unique combination of character states (see below, main Discussion), justifying the described new genus.

\section{Cladotypic nomenclature}

Taxon Pteroliriope Cui, Béthoux, Kondratieff, Shih \& Ren, tax. nov.

Definition: Species that evolved from the hypothetical ancestral species in which the character state in forewing, AA2 with more than three branches (as opposed to 'in forewing, AA2 with three branches, or less'), as exhibited by californica Newport, 1851 and princeps
Banks, 1907, has been acquired (venation designations as herein).

Etymology: See above.

Cladotypes: Specimen MNHN-EP663 (belonging to californica Newport, 1851 [15], male), and specimen MNHN-EP667 (belonging to princeps Banks, 1907 [16], male).

Paracladotypes: Specimens MNHN-EP664 to -EP666 (belonging to californica Newport, 1851 [15], two males, one female), and specimens MNHN-EP668 to -EP670 (belonging to princeps Banks, 1907 [16], two males, one female).

Composition: All recent species currently assigned to the genus Pteronarcys (see [17]) and sinitshenkovae sp. nov.

Discussion: Wings of both cladotypic species have been illustrated in a former publication [1]. Systematic aspects are treated under the traditional heading (see above). As for a possible earlier association of the 


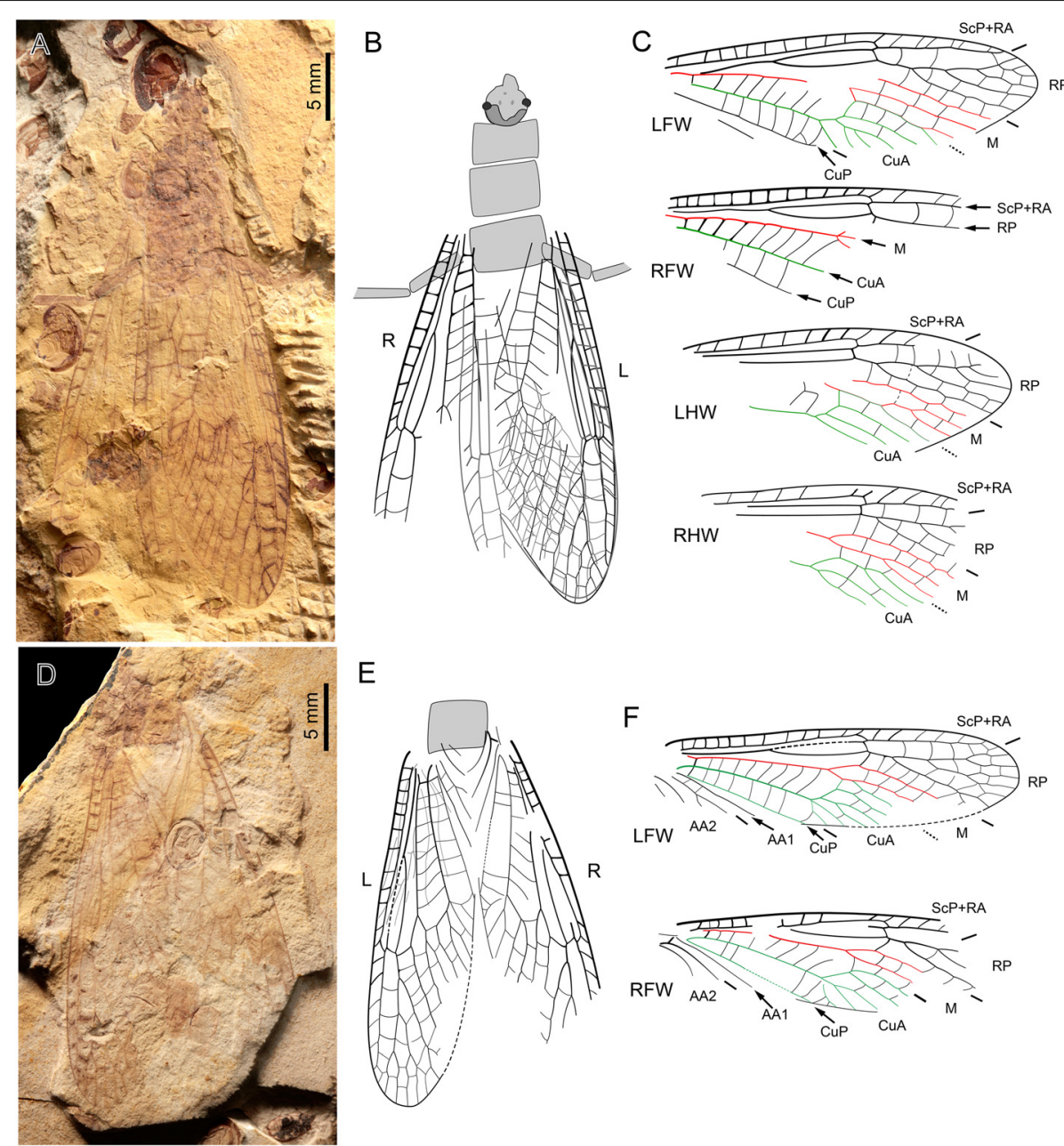

Fig. 4 Pteroliriope sinitshenkovae tax. et sp. nov. (Middle Jurassic; Daohugou, China). a-c, Specimen CNU-PLE-NN-2013003; (a), Photograph (negative imprint); (b-c), Drawings; (d-f), Specimen CNU-PLE-NN-2013002; (d), Photograph (positive imprint); (e-f), Drawings

proposed defining character state alone with a taxon (named, or not), we found none.

Taxon Pteronarcys nom. Newman, 1838, Cui, Béthoux \& Kondratieff dis.-typ. nov.

Definition: Species that evolved from the hypothetical ancestral species in which the character state in forewing, area between R/RP and $M$ basal to the fork of $M$ broad, with cross-veins' (as opposed to 'in forewing, area between $\mathrm{R} / \mathrm{RP}$ and $\mathrm{M}$ basal to the fork of $\mathrm{M}$ of regular width, without cross-veins'), as exhibited by californica Newport, 1851 and princeps Banks, 1907, has been acquired (venation designations as herein).

Cladotypes: Specimen MNHN-EP663 (belonging to californica Newport, 1851 [15], male), and specimen MNHN-EP667 (belonging to princeps Banks, 1907 [16], male).

Paracladotypes: Specimens MNHN-EP664 to -EP666 (belonging to californica Newport, 1851 [15], two males, one female), and specimens MNHN-EP668 to -EP670 (belonging to princeps Banks, 1907 [16], two males, one female).

Composition: All recent species currently assigned to the genus Pteronarcys (see [17]). The species sinitshenkovae sp. nov. can be conclusively excluded from this taxon (see below).

Discussion: Wings of both cladotypic species have been illustrated in an earlier publication [1]. The character state defining the taxon Pteronarcys (name first erected in Newman, 1837 [10]) can be seen as composed of two characters regarding the area between R/RP and $\mathrm{M}$, and basal to the fork of $\mathrm{M}$, viz. its width (regular vs. broad), and the occurrence of cross-veins (absent vs. present). However, to our knowledge, the state 'area of regular width' always co-occurs with the state 'crossveins absent', and the state 'area broad' always co-occurs with the state 'cross-veins present'. Indeed a broadening of the space between two veins is likely to decrease the 

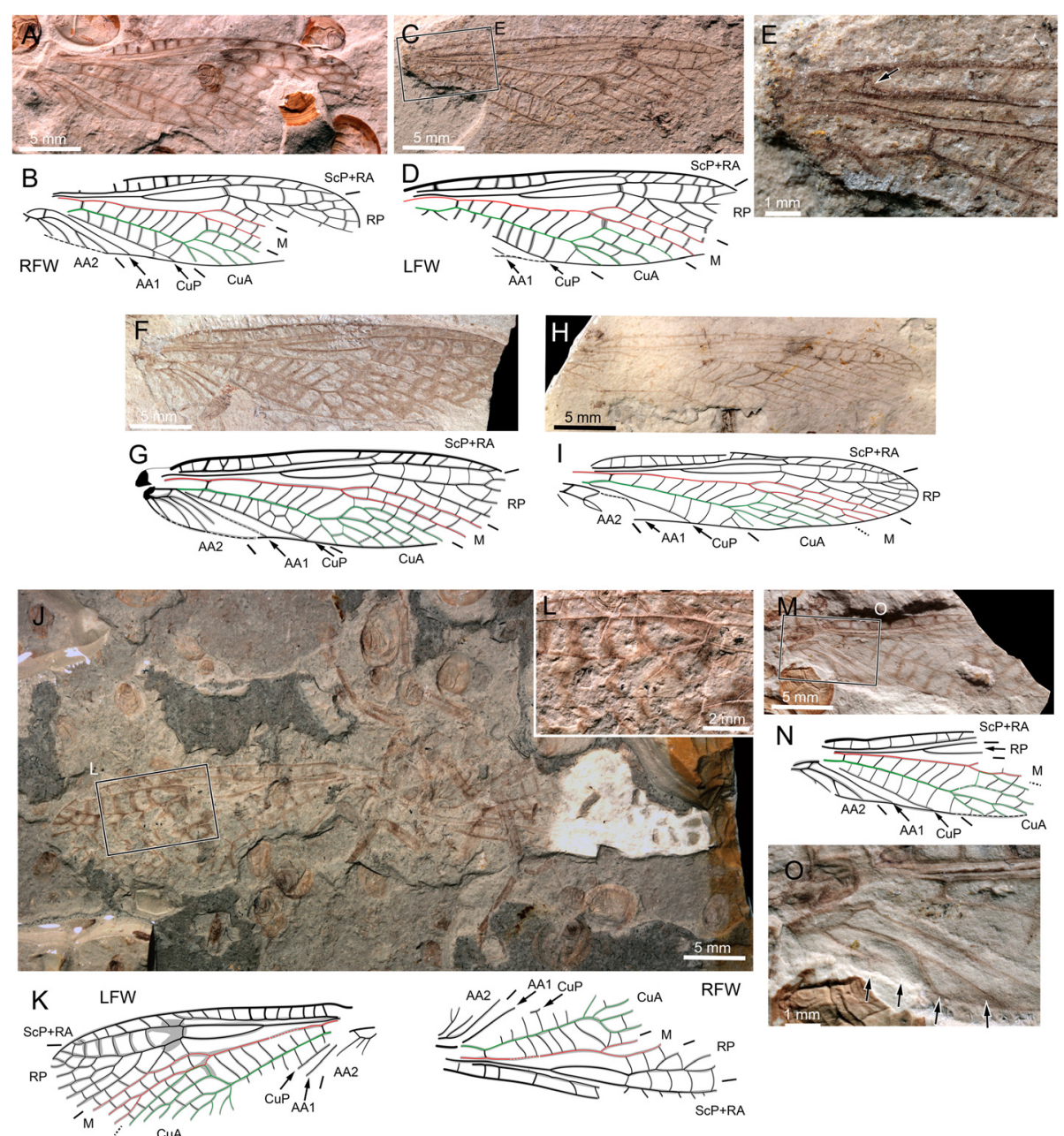

Fig. 5 Pteroliriope sinitshenkovae tax. et sp. nov. (Middle Jurassic; Daohugou, China). a-b, Specimen CNU-PLE-NN-2013024; (a), Photograph (positive imprint, right forewing); (b), Drawing; (c-e), Specimen CNU-PLE-NN-2013021; (c), Photograph (negative imprint); (d), Drawing; (e), Detail of anterior-basal area (as located on c), the arrow indicates the 'systellognathan' basal oblique cross-vein; (f-g), Specimen CNU-PLE-NN-2013020; (f), Photograph (positive imprint); (g), Drawing; (h-i), Specimen CNU-PLE-NN-2013006; (h), Photograph (positive imprint); (i), Drawing; (j-I), Specimen CNU-PLE-NN-2013032; (j-k), Photograph (positive imprint of left forewing and negative imprint of right forewing) and drawings; (I), Detail photo of coloration in LFW, as located on (j); ( $\mathbf{m}-\mathbf{o})$, Specimen CNU-PLE-NN-2013019; ( $\mathbf{m}-\mathbf{n})$, Photograph (positive imprint, reversed) and drawing; (o), Detail of basal part of forewing, arrows showing branches of AA2, as located on ( $\mathbf{m})$

repression of cross-veins formation. In other words, the two conditions are most likely correlated.

Our literature survey revealed no earlier association of the proposed defining character state along with a taxon (named or not, we found no mention of the defining character state). Because the composition of the taxon herein defined matches that of the genus Pteronarcys, we propose to adapt this name under cladotypic nomenclature.

\section{Species-level systematics}

Pteroliriope sinitshenkovae Cui, Shih, \& Ren, sp. nov. (Figs. 2, 3, 4, 5, 6, 7 and 9A.2)

(urn:Isid:zoobank.org:act:94D0E24A-C812-4C83-8951BB4DA7661EFA)
Diagnosis: Forewing: area between R/RP and M basal to the fork of $M$ of regular width, without cross-veins (shared with Pteronarcella spp.; opposite condition in Pteronarcys spp.); MA distinct from RP (shared with Pteronarcella spp., fusion occasionally present in Pteronarcys spp.); AA2 with more than 3 branches (shared with Pteronarcys spp; less than 3 branches in Pteronarcella spp.); except for the $\mathrm{aa}_{1}-\mathrm{aa}_{2}$ cross-vein, no crossvein between AA2 branches (cross-veins present in both Pteronarcella spp. and Pteronarcys spp.). Hind wing: CuA branched (simple in Pteronarcella spp., branched in Pteronarcys spp.).

Etymology: The specific eptithet honours Dr. N. Sinitshenkova, for her important contributions to the study of fossil stoneflies. 

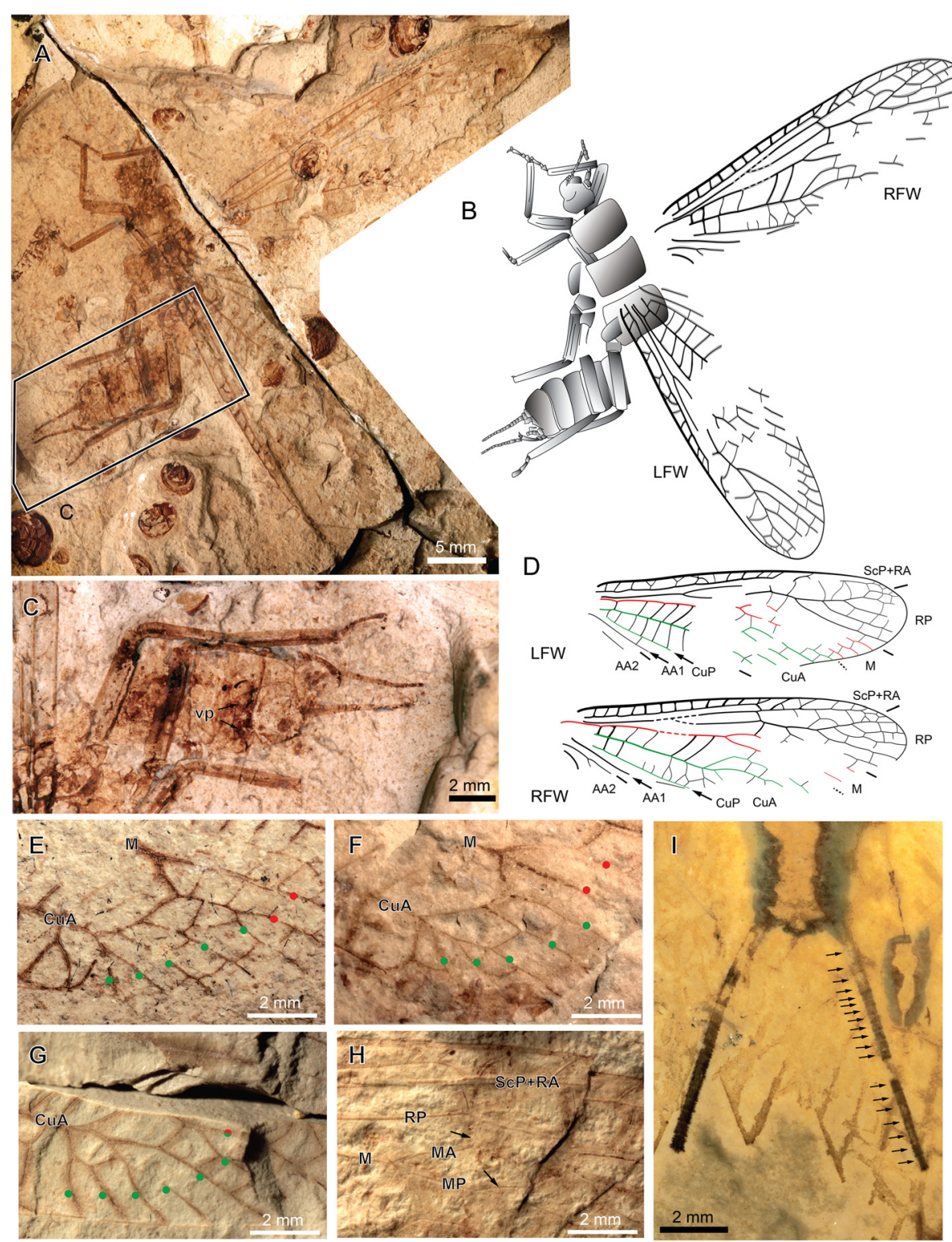

Fig. 6 Pteroliriope sinitshenkovae tax. et sp. nov. (Middle Jurassic; Daohugou, China). a-d, Specimen CNU-PLE-NN-2013005; (a), Photograph (positive imprint); (b,d), Drawings; (c), Detail of the end of abdomen and legs, as located on (a); (e-h), Photographs of detail forewing venation variability, branches of M are indicated by red spots, branches of CUA are indicated by green spots; (e), Specimen CNU-PLE-NN-2013007; (f), Specimen CNUPLE-NN-2013008; (g), Specimen CNU-PLE-NN-2013027; (h), Specimen CNU-PLE-NN-2013026; (i), Detail of cerci of specimen CNU-PLE-NN-2013011

Material: Holotype specimen: CNU-PLE-NN-2015 001; paratype specimens: CNU-PLE-NN-2013001, CNUPLE-NN-2013005; other specimens: CNU-PLE-NN-2013 002 - CNU-PLE-NN-2013004, CNU-PLE-NN-2013006 CNU-PLE-NN-2013008, CNU-PLE-NN-2013011, CNU-P LE-NN-2013019 - CNU-PLE-NN-2013021, CNU-PLE-N N-2013024, CNU-PLE-NN-2013026, CNU-PLE-NN-2013 027, CNU-PLE-NN-2013032, CNU-PLE-NN-2013036.

Locality: near Daohugou Village, Ningcheng County, Inner Mongolia, China; Jiulongshan Formation; late Middle Jurassic [18-20].
General description: Body: total length (excluding antennae and cerci) ca. $25 \mathrm{~mm}$; head narrower than prothorax, with basal part broader than distal part; antennae filiform; three ocelli; eyes round, dark-coloured; prothorax, mesothorax and metathorax of similar rectangular shape, width about 1.5 times long as length; forelegs shortest, hind legs longest; femur robust; tibia slender; tarsus with three segments, second one shortest, third one (pretarsus) longest; pretarsus with a pair of simple claws; cerci multi-segmented. Forewings: average length $28.1 \mathrm{~mm}$ (longest $31.4 \mathrm{~mm}$ in specimen CNU- 

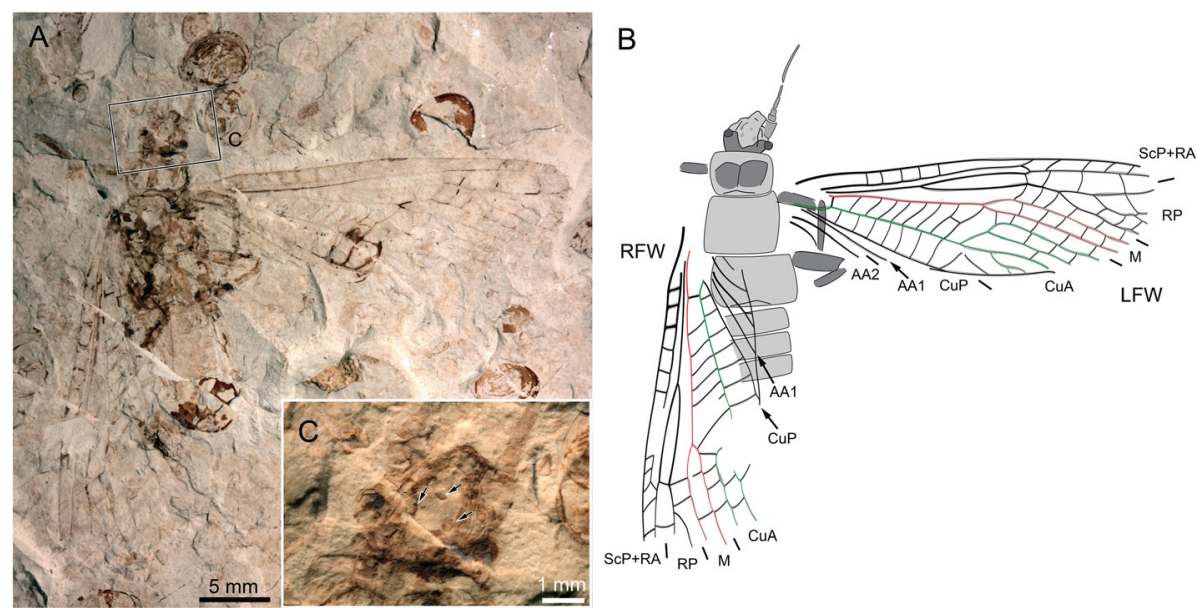

Fig. 7 Pteroliriope sinitshenkovae tax. et sp. nov. (Middle Jurassic; Daohugou, China), specimen CNU-PLE-NN-2013036; (a), Photograph (negative imprint); (b), Drawing; (c), Detail of head, arrows showing three ocelli, as located on (a)

PLE-NN-2013011, shortest $24.1 \mathrm{~mm}$ in specimen CNUPLE-NN-2013035), average width $7.5 \mathrm{~mm}$ (widest $8.8 \mathrm{~mm}$ in specimen CNU-PLE-NN-2013029, narrowest $(5.7 \mathrm{~mm})$ in specimen CNU-PLE-NN-2013015) (dimensions based on 18 specimens preserving almost-complete forewings); occurrence of a strong oblique cross-vein present in area between the anterior wing margin and $\mathrm{ScP}$ close to wing base (Fig. 5c-e); more distally, area between anterior margin and ScP filled with strong cross-veins; $\mathrm{ScP}$ reaches RA at second third of wing length; several cross-veins (branches from ScP + RA?) occurring between $\mathrm{ScP}+\mathrm{RA}$ and anterior margin; RA-RP fork in second fifth of wing length; area between RA and RP with a constriction opposite ra-rp cross-vein; RP with 4-8 branches (including distalmost one or two); in area between RA and RP, first cross-vein slightly basal to the end of ScP on RA, stronger than other following cross-veins; $M$ bent downward slightly before its fork; fork located near wing mid-length; MA mostly simple; MP simple or forked; a strong cross-vein (arculus) between base of $\mathrm{M}$ and $\mathrm{CuA}$; $\mathrm{CuA}$ forked distally, slightly basal to the fork of $\mathrm{M}$; $\mathrm{CuA}$ with 4(3?)-8 branches; CuP straight, simple; AA1 simple; AA2 normally with 4 branches, with varying branching pattern; dark pigmentation along most of venation, especially obvious along ra-rp cross-vein, cross-veins in area between anterior wing margin and $\mathrm{ScP}$, and RP at its fork. Hind wings: visible parts very similar to forewings except: area between anterior wing margin and $\mathrm{ScP}+\mathrm{RA}$, slightly wider; and $\mathrm{CuA}$ with 3 (2?) branches.

Specimen descriptions: Specimen CNU-PLE-NN2015001 (holotype; Fig. 2): complete individual, male, positive and negative imprints, wings partly overlapping. Body: posterior margin of head $4.5 \mathrm{~mm}$ long; outline of mouthpart visible; antennae with 28 segments preserved; prothorax $3.0 \mathrm{~mm}$ long, $4.9 \mathrm{~mm}$ wide; mesothorax
$3.5 \mathrm{~mm}$ long, $5.0 \mathrm{~mm}$ wide; metathorax $3.5 \mathrm{~mm}$ long, $5.5 \mathrm{~mm}$ wide; femur of foreleg about $4.0 \mathrm{~mm}$ long, $1.0 \mathrm{~mm}$ wide; tibia not completely preserved, $0.6 \mathrm{~mm}$ wide; femur of right mid-leg $3.5 \mathrm{~mm}$ long, $1.7 \mathrm{~mm}$ wide; tibia of left mid-leg $7.0 \mathrm{~mm}$ long, $0.5 \mathrm{~mm}$ wide; femur of left hind leg about $5.0 \mathrm{~mm}$ long, $1.0 \mathrm{~mm}$ wide; tibia of right hind leg $7.0 \mathrm{~mm}$ long, $0.7 \mathrm{~mm}$ wide; tarsus 3segmented; first segment $1.0 \mathrm{~mm}$ long, second segment $0.5 \mathrm{~mm}$ long, third segment (pretarsus) $1.1 \mathrm{~mm}$ long; abdomen completely preserved; ninth sternite, posterior edge of tergum with two hook-like structures consisting of three lobes; anterior hemitergal lobe (ahl) comparatively long and narrow, well separated from median lobe (mhl); mhl and posterior (phl) hemitergal lobes processes; tenth tergum divided mid-dorsally into two hemitergites; each hemitergite not clearly separated from each other, with posterior lobe small and pointed; inner part (ip) of supra-anal process visible; two lateral braces (lb) at the apex of ip, very broad; paragenital plate (pgp) with anterior lateral edged terminating close to lateral braces (lb); apical region of dorsal section of supra-anal process (ads) partly visible; eleventh segment divided into two hook-like sub-anal lobes (sbl). Left forewing: $30.0 \mathrm{~mm}$ long and $7.9 \mathrm{~mm}$ wide; base of $\mathrm{Cu}$ and most part of anal area not visible. Right forewing: $25.4 \mathrm{~mm}$ long and $10.0 \mathrm{~mm}$ wide as preserved; anterior-distal area not preserved; posterior-basal area not visible except $\mathrm{CuP}$ and AA1. Left hind wing: $28.5 \mathrm{~mm}$ long, $8.9 \mathrm{~mm}$ wide as preserved; $\mathrm{CuA}$ mostly not visible; AA2 with 4 branches reaching posterior margin visible. Right hind wing: $20.0 \mathrm{~mm}$ long, $9.0 \mathrm{~mm}$ wide as preserved; distal part of wing not preserved; area between anterior branch of $\mathrm{M}$ and three posterior branches of AA2 not identifiable.

Specimen CNU-PLE-NN-2013001 (paratype; Fig. 3a-c): four wings overlapping. Left forewing: $29.6 \mathrm{~mm}$ long and 
$6.9 \mathrm{~mm}$ wide as preserved; base of $\mathrm{Cu}$ not visible. Right forewing: $27.1 \mathrm{~mm}$ long and $7.9 \mathrm{~mm}$ wide as preserved, with very basal and posterio-distal part not visible; arculus, branches of $\mathrm{CuA}$, and basal forks of AA2 not visible. Hind wings: $\mathrm{CuA}$ with 3 branches. Left hind wing: $24.0 \mathrm{~mm}$ long and $8.5 \mathrm{~mm}$ wide as preserved; fork of $\mathrm{R}$ and $\mathrm{M}$ not visible; distal part of $\mathrm{CuP}$ and $\mathrm{AA} 1$ visible. Right hind wing: $22.1 \mathrm{~mm}$ long, $8.5 \mathrm{~mm}$ wide as preserved.

Specimen CNU-PLE-NN-2013004 (Fig. 3d-f): Head and thorax preserved with all three pairs of legs; foreand hind wing overlapping on both sides. Left forewing: $24.9 \mathrm{~mm}$ long, $7.0 \mathrm{~mm}$ wide preserved, with distal part, posterior margin and anal area not visible. Right forewing: $23.5 \mathrm{~mm}$ long, $7.7 \mathrm{~mm}$ wide as preserved; MP forked. Left hind wing: basal part and posterior margin not visible; $22.6 \mathrm{~mm}$ long and about $8.0 \mathrm{~mm}$ wide as preserved. Right hind wing: veins partly visible, basal and distal part missing; $19.8 \mathrm{~mm}$ long and $8.6 \mathrm{~mm}$ wide as preserved.

Specimen CNU-PLE-NN-2013003 (Fig. 4a-c): Head, thorax and hind legs preserved, four wings overlapping, in resting position. Left forewing: about $32.0 \mathrm{~mm}$ long, and $10.6 \mathrm{~mm}$ wide, as preserved; basal part uninterpretable. Right forewing: $27.0 \mathrm{~mm}$ long and $9.7 \mathrm{~mm}$ wide as preserved; mid-anterior part visible. Left hind wing: $29.3 \mathrm{~mm}$ long, $10.9 \mathrm{~mm}$ wide. Right hind wing: $24.6 \mathrm{~mm}$ long, $11.6 \mathrm{~mm}$ wide; MP forked.

Specimen CNU-PLE-NN-2013002 (Fig. 4d-f): a pair of wings in resting position, with a few veins of left hind wing visible. Left forewing: nearly complete, $26.4 \mathrm{~mm}$ long, $6.9 \mathrm{~mm}$ wide; MP forked. Right forewing: incompletely preserved, with distal part missing; $22.7 \mathrm{~mm}$ long, $7.0 \mathrm{~mm}$ wide; as preserved, MP simple.

Specimen CNU-PLE-NN-2013024 (Fig. 5a-b): positive imprint of right forewing; $27.6 \mathrm{~mm}$ long and $7.5 \mathrm{~mm}$ wide; $\mathrm{CuA}$ with 5 branches, all distinct from $\mathrm{M}$.

Specimen CNU-PLE-NN-2013021 (Fig. 5c-e): negative imprint of left forewing; $26.6 \mathrm{~mm}$ long and $7.6 \mathrm{~mm}$ wide as preserved; $\mathrm{CuA}$ with 5 branches, all distinct from $\mathrm{M}$.

Specimen CNU-PLE-NN-2013020 (Fig. 5f-g): positive and negative imprint of right forewing; $30.3 \mathrm{~mm}$ long and $7.8 \mathrm{~mm}$ wide as preserved; coloration well preserved; $\mathrm{CuA}$ with 6 branches, all distinct from M; cross-veins in the area between $\mathrm{CuA}$ and $\mathrm{CuP}$ reticulated.

Specimen CNU-PLE-NN-2013006 (Fig. 5h-i): positive imprint of a nearly complete right forewing; $29.4 \mathrm{~mm}$ long, $6.0 \mathrm{~mm}$ wide; MP forked; $\mathrm{CuA}$ with 5 branches, one fused with MP.

Specimen CNU-PLE-NN-2013032 (Fig. 5j-1): positive imprint of left forewing and negative imprint of right forewing, with scattered legs. Left forewing: $26.5 \mathrm{~mm}$ long and $8.6 \mathrm{~mm}$ wide as preserved; MP forked; $\mathrm{CuA}$ with 8 branches, one fused with MP; Right forewing: $23.2 \mathrm{~mm}$ long, $8.6 \mathrm{~mm}$ wide as preserved.
Specimen CNU-PLE-NN-2013019 (Fig. 5m-o): positive imprint of left forewing; $19.4 \mathrm{~mm}$ long and $6.9 \mathrm{~mm}$ wide as preserved; $\mathrm{CuA}$ with a branch fused with MP; base very well preserved, with 4 distinct branches of AA2.

Specimen CNU-PLE-NN-2013005 (paratype; Fig. 6a-d): nearly complete body and both forewings preserved, female. Body: basal part of head $2.3 \mathrm{~mm}$ long; antennae with 8 segments preserved; prothorax $3.2 \mathrm{~mm}$ long, $4.7 \mathrm{~mm}$ wide; mesothorax $2.9 \mathrm{~mm}$ long, $4.6 \mathrm{~mm}$ wide; metathorax largest, $3.6 \mathrm{~mm}$ long, $5.4 \mathrm{~mm}$ wide; forelegs well preserved; femur about $4.3 \mathrm{~mm}$ long, $1.0 \mathrm{~mm}$ wide; tibia about $4.6 \mathrm{~mm}$ long, $0.6 \mathrm{~mm}$ wide; femur of mid-leg about $3.9 \mathrm{~mm}$ long, $0.9 \mathrm{~mm}$ wide; tibia of mid-leg $5.0 \mathrm{~mm}$ long, $0.6 \mathrm{~mm}$ wide; femur of hind leg about $4.9 \mathrm{~mm}$ long, $0.9 \mathrm{~mm}$ wide; tibia of hind leg $7.0 \mathrm{~mm}$ long, $0.7 \mathrm{~mm}$ wide; eight sternite with two round vaginal projections (vp, in Fig. 6c). Left forewing: $26.9 \mathrm{~mm}$ long, $8.0 \mathrm{~mm}$ wide; MP probably forked; Right forewing: $29.3 \mathrm{~mm}$ long, $7.4 \mathrm{~mm}$ wide.

Specimen CNU-PLE-NN-2013036 (Fig. 7a-c): half body and both forewings preserved; head $3.5 \mathrm{~mm}$ wide between compound eyes; prothorax $3.1 \mathrm{~mm}$ long, $4.6 \mathrm{~mm}$ wide; mesothorax $3.9 \mathrm{~mm}$ long, $5.2 \mathrm{~mm}$ wide; metathorax $3.4 \mathrm{~mm}$ long, $6.1 \mathrm{~mm}$ wide; three abdominal segments visible. Left forewing: $26.1 \mathrm{~mm}$ long, $8.3 \mathrm{~mm}$ wide as preserved; Right forewing: preserved $22.4 \mathrm{~mm}$ long, $8.2 \mathrm{~mm}$ wide.

Discussion: The interpretation of the genitalia of specimen CNU-PLE-NN-2015001 is based on a comparison with the description of extant taxa of the Pteronarcyidae by Nelson and Hanson (1971; [14]) on extant Pteronarcyidae, and is included in the main Discussion section.

The distinction between the conditions 'branched MP' and 'fusion of a branch of CuA with MP' proved difficult to confirm in several cases. For example, in the case of the specimen CNU-PLE-NN-2013002, the left forewing is interpreted to have a branch of $\mathrm{CuA}$ fused with MP (Fig. 4f), but a branched MP remains a plausible interpretation, given that the presumed MP fork is located in a very basal position. However, the branching pattern of $\mathrm{CuA}$ in the forewing shows variation in the number of branches, usually with four to five branches, rarely with three (Fig. 3f) or six or more (Figs. 4c, 5g, k and 6g).

We found no reason to distinguish different species within the fossils we examined. Data on extant species of Pteronarcys ([1]; below considered as closely related to the new fossil species) show that the observed size variation, and the occurrence of a branched MP, is subjected to intra-specific variation. The branching pattern of AA2 in forewing of Pteronarcyidae (with which the new species is closely related, see below) also shows a certain degree of variation, in particular in Pteronarcys spp. (see Figs. 23, 24 in [21]), which can also be observed in the fossil specimens: the first branch of AA2 can be simple or forked (Fig. 4f, compare LFW and RFW); and the first branch of 
AA2 $\alpha$ branched distally or proximally (compare Fig. 5b and $\mathrm{g}$ ). Therefore, the assignment of all the specimens listed above to a single species is well supported.

\section{Discussion}

Before proceeding with the evolutionary implications of our discovery, a note on nomenclatural aspects is necessary. Under the cladotypic nomenclature all taxon names are written in italics with a capital letter. Traditional genus names and cladotypic names can therefore be confused. However, the name of the newly erected genus (viz., 'Pteroliriope') is also used in association with a cladotypic definition. Consequently the combination 'Pteroliriope sinitshenkovae' is valid under both procedures. In addition the adaptation of the pre-existing genus name 'Pteronarcys' under cladotypic nomenclature leaves the association of this name with the specific epithets of its constituent species unchanged (e.g., 'Pteronarcys californica'). In such cases both procedures reach a similar outcome [22]. However the cladotypic procedure has that advantage that the exclusion of sinitshenkovae from the taxon Pteronarcys can be made explicit with the minimal combination 'Pteroliriope nec Pteronarcys sinitshenkovae' (this cannot be achieved under the traditional procedure without inflating ranks [23] and a good knowledge of the corresponding group systematics). Unless mentioned, this section will be further continued under the cladotypic framework. In other words, all taxon names written in italics are to be understood as cladotypic names. Species are referred to by their specific epithet associated with authorship data (also known as Lanham species names).

\section{Systematic affinities of Pteroliriope sinitshenkovae tax. et} sp. nov.

The distribution of the states of selected characters is summarized in Fig. 8. At first glance, the state in the distal half of the wing, in the areas between branches of $\mathrm{M}$ and $\mathrm{CuA}$, occurrence of numerous cross-veins' (as opposed to 'no cross-veins') is a very distinctive trait (orange on Fig. 8a). This trait is shared with carpenteri Béthoux et al., 2011 [1], which is sister-group related to all other Plecoptera, with most Antarctoperlaria (with the exception of some Gripopterygidae), and, within the Systellognatha, with some Perlidae, zhaoi Liu et al. 2007 [24] (a fossil Systellognatha of unclear affinities [3]), and the Pteronarcyidae.

The occurrence of a short, oblique strong first crossvein in the area between the anterior wing margin and ScP (arrow on Fig. 5c-e) allows the assignment of sinitshenkovae sp. nov. to the Systellognatha, as this state is unique to the group (orange on Fig. 8b). The character state 'in hind wing, CuA branched' (as opposed to 'simple') is congruent with the previous one: indeed this state occurs only in some Diamphipnoidae and in Systellognatha (with the exception of species of the genus Pteronarcella; state distribution not represented on Fig. 8). The assignment of sinitshenkovae tax. et sp. nov. to the Systellognatha, and, more specifically to the Pteronarcyidae, is well corroborated.
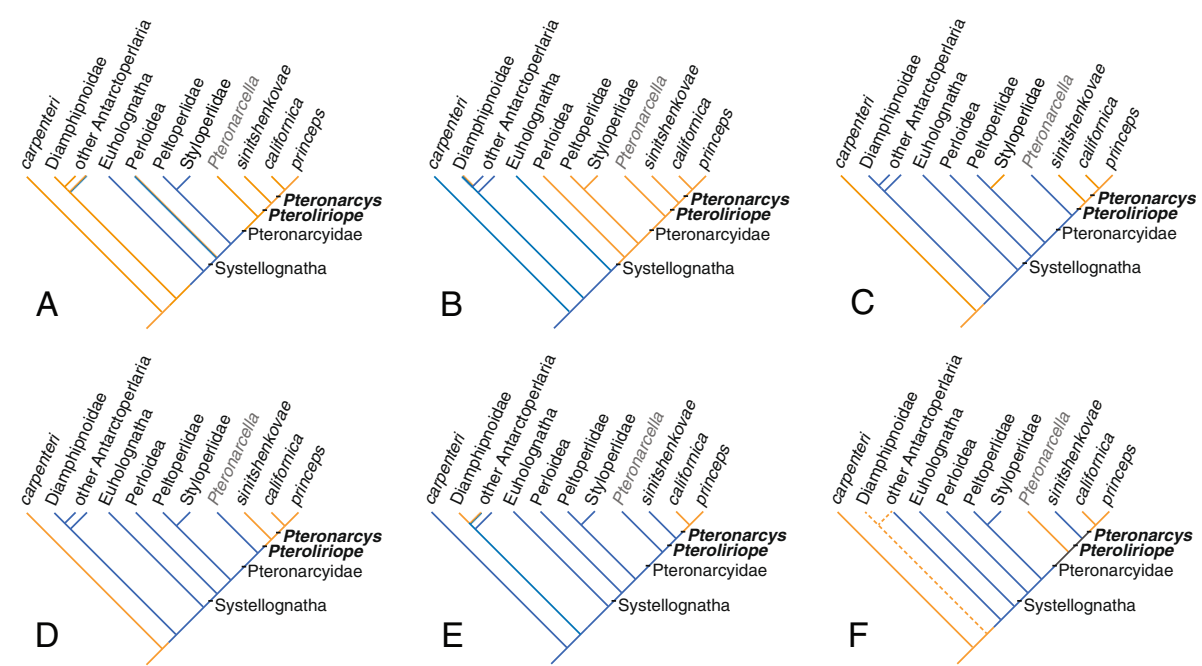

Fig. 8 Distribution of selected character states, (phylogeny after [32], complemented by data from [1] and [41]; 'Pteroliriope' placed as under the cladotypic approach, i.e. it is a taxon which includes the species sinitshenkovae sp. nov. and the taxon Pteronarcys dis.-typ. nov.). a, In the distal half of the wing, in the areas between branches of $\mathrm{M}$ and CuA, crossveins absent (blue) vs. numerous (orange); (b), First cross-vein in the area between the anterior wing margin and ScP not short, strong and oblique (blue) vs. short, strong and oblique; (c), Forewing, number of AA2 branches, three or less (blue) vs. more than three (orange); (d), Fore- and hind wing, M occasionally with more than two branches, no (blue) vs. yes (orange); (e), Forewing, area between R/RP and M basal to the fork of M with regular width and without cross-veins (blue) vs. broad and with cross-veins (orange); (f), Forewing, cross-veins in the areas between branches of AA2, none occurring (blue) vs. occurring (orange) 
The character state 'in forewing, AA2 with more than three branches' (as opposed to 'with three or fewer branches'; orange on Fig. 8c) confirms this statement: among Plecoptera it is known only in carpenteri, the Styloperlidae (see below), and Pteronarcys spp. It is noted that AA1 is seemingly forked in Styloperlidae (Fig. 6 in [25]; unpubl. data). However, given that AA1 is simple in all other Plecoptera, we assume that a fusion of the anterior-most branch of AA2 with AA1 occurs in the Styloperlidae. This interpretation implies an AA2 with more than 3 branches in the family.

Another useful character state is in fore- and hind wing, $\mathrm{M}$ occasionally with more than two branches' (as opposed to 'with two branches only'; orange on Fig. 8d). Among Plecoptera, this state occurs only in carpenteri and Pteronarcys spp. (pers. obs. as for the hind wing). Affinities of the new species with Pteronarcys spp. are further confirmed by its large size. According to Stewart \& Stark (2008; [26]), among the Pteronarcyidae, a body length above $23 \mathrm{~mm}$ is diagnostic of the genus Pteronarcys (less than $20 \mathrm{~mm}$ in species of the genus Pteronarcella). The species sinitshenkovae sp. nov., with a body length of $25 \mathrm{~mm}$, is then likely to be closely related to this genus (although body size is perhaps not an ideal diagnostic character state). Also, both sinitshenkovae sp. nov. and Pteronarcys spp. have an area between RA and RP in the forewing with a constriction opposite the ra-rp cross-vein, a trait absent in Pteronarcella badia (Fig. 1a, b, e, f).

Finally sinitshenkovae sp. nov. lacks a character state shared by all Pteronarcys spp., namely in forewing, area between R/RP and $M$ basal to the fork of $M$ broad, with cross-veins' (as opposed to 'without cross-veins'; orange on Fig. 8e; cross-veins present in Diamphipnoidae and some other large-sized Antarctoperlaria). It can then be excluded from this genus. The proposed new genus (and species) is therefore supported.

We have examined the relevance of additional characters. The occurrence of cross-veins between branches of AA2 has been indicated as diagnostic of the Pteronarcyidae [26]. However this state is not present in sinitshenkovae sp. nov. (Fig. 8f). Given the number of character states supporting the close affinities of this species with Pteronarcys spp., we assume that the occurrence of crossveins in the anal area is homoplasic within Pteronarcyidae.

Regarding characters of external morphology other than wing venation, Stewart \& Harper (1996; [27]) list the occurrence of three ocelli as diagnostic of the Pteronarcyidae (this character is later abandoned [26]). Three ocelli are present in sinitshenkovae sp. nov. but its phylogenetic relevance is unclear as this condition is widespread among Plecoptera.

We have also attempted to interpret the male terminalia of sinitshenkovae sp. nov. based on the very wellpreserved specimen CNU-PLE-NN-2015001 (Fig. 2d,d') and on data on terminalia of extant species [14]. We need to emphasize here that the interpretation of terminalia in fossil insect imprints is made difficult by the overlap of elements initially located at different levels. Inconclusive attempts have been made on material from the same locality [28].

We propose to compare the fossil species (Fig. 9a.2) with badia (Fig. 9a.1) and Pteronarcys scotti Ricker, 1952 ([29]) (Fig. 9a.3). The various elements we identified in sinitshenkovae sp. nov. were more easily matched with those recognized in badia. For example, both sinitshenkovae sp. nov. and badia possess well-developed lateral braces (lb; turquoise on Fig. 9a) and pointed paragenital plates (pgp; orange). We focused on the lobes of the hemitergites of the tenth segment (composed of ahl, mhl, and phl; green on Fig. 9a), because they exhibit an elaborate shape. In badia the hemitergites of the tenth tergum are mediodorsally divided into two lobes (Fig. 9a.1). In Pteronarcys scotti three lobes can be identified (Fig. 9a.3). In sinitshenkovae sp. nov. three lobes can be identified (Fig. 9a.2), but their shapes differ strongly from those in Pteronarcys scotti. We considered a number of hypotheses of topographic homology and selected the most parsimonious one (i.e., the one implying the smallest amount of transformations). To assist comparison we opted for the following color-coding: ahl, light green; mhl, middle green; phl, dark green; a lobe herein assumed to encompass both mhl and phl (undifferentiated) is indicated by shaded limits (Fig. 9b).

In order to explain the occurrence of two lobes in badia and three in Pteronarcys scotti, one possibility is that the posterior-most lobe in the former divides into two (which then are mhl and phl). Under this scenario (Fig. 9b) sinitshenkovae sp. nov. can be interpreted as exhibiting an intermediate condition, with the pointed, posterior process being a weakly individualized phl. In summary the development of phl would compose an apomorphy shared by sinitshenkovae sp. nov. and Pteronarcys spp. This hypothesis suggests that a long and narrow ahl is a plesiomorphy (it is present in badia, sinitshenkovae sp. nov., and most species of Pteronarcys). This investigation supports the view that Pteroliriope sinitshenkovae tax. et sp. nov. is more closely related to Pteronarcys spp. than to species of the genus Pteronarcella, a hypothesis already supported by characters evaluated above.

\section{Evolutionary implications}

Most contributions on the systematics of fossil stoneflies make extensive use of paraphyletic taxa. This approach is an impediment for current approaches focusing on divergence date estimates, because the support for the placement of particular fossil species cannot be easily evaluated. Also, the positive identification of fossil 

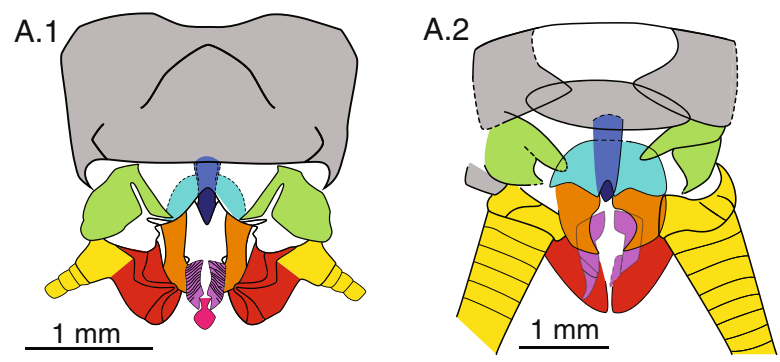

A.3
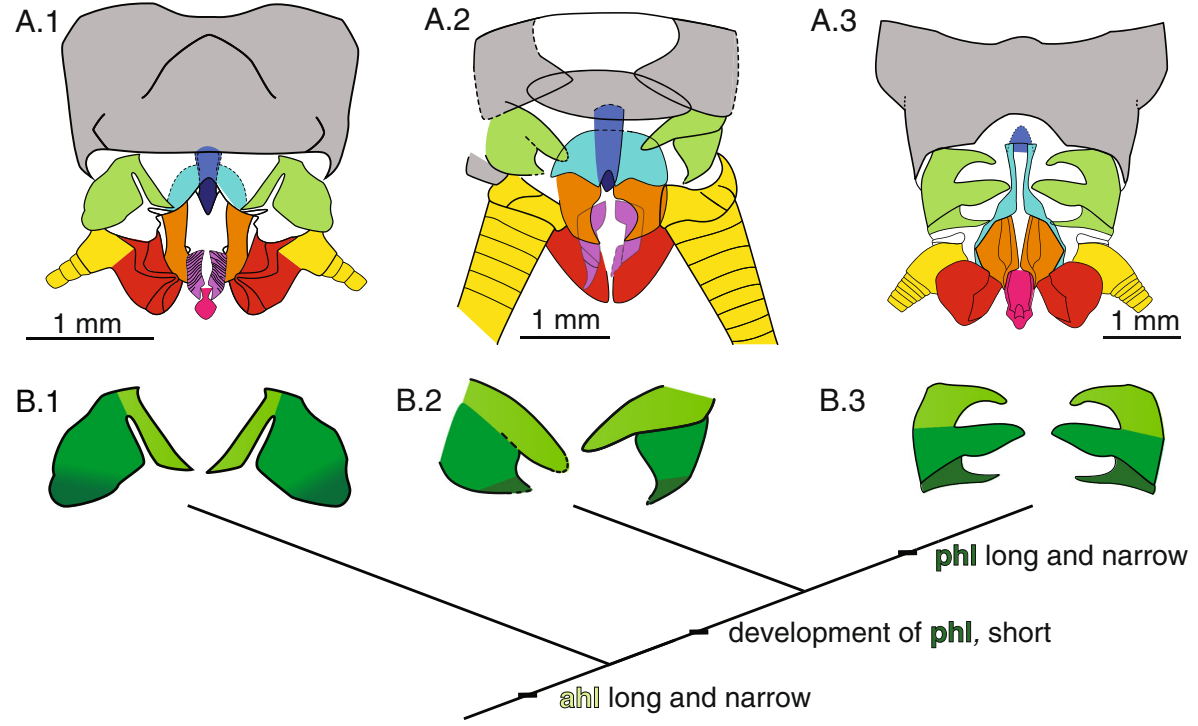

Fig. 9 Comparation of posterior part of male postabdomen of three species (including Pteroliriope sinitshenkovae tax. et sp. nov.) belonging to all known genera of the family Pteronarcyidae (a), with same color coding for the same segments $\left(9^{\text {th }}\right.$ segment, gray; hemitergal lobe, green; ahl, light green; mhl, moderate green; phl, dark green; ip, dark blue; lb, light blue; pgp, orange; sbl, red; abs, purple; sa, pink; cerci, yellow), and the hypothesis of evolution of segments of the hemitergal lobes (b). a.1, b.1, Pteronarcella badia (Hagen, 1874) [12], modified from Fig. 35 in [14]; a.2, b.2, Pteroliriope sinitshenkovae tax. et sp. nov.; a.3, b.3, Pteronarcys scotti Ricker, 1952 [29], modified from Fig. 64 in Nelson and Hanson, 1971

Antarctoperlaria is hindered by the lack of data on putative derived character states in the wing venation. Yet the fossil record indicates that by the Jurassic, crownPlecoptera had already experienced a sequence of divergence events. Among the Euholognatha, both lineages Leuctrida and Capniida were already present $[5,6,30]$ (the earliest known Leuctrida, culonga Sinitshenkova, 2011 [31], is Triassic). The discovery of Pteroliriope nec Pteronarcys sinitshenkovae complements this approach for the Systellognatha, for which divergence dates have been difficult to estimate. It demonstrates that the Pteronarcyoidea and the Perloidea (sensu Zwick, 2000 [32]) had already diverged ca. 165 million years ago, and that divergence events within the Pteronarcyoidea had already occurred.

Given that the earliest members of a given lineage are unlikely to be recovered from the fossil record, the recently proposed 170 million years divergence date estimate between the two major lineages of Plecoptera (viz. Antarctoperlaria, and Euholognatha \& Systellognatha) proposed by Misof et al. (2014; [33]) clearly is an underestimate, given that sinitshenkovae is nested well within the Systellognatha Therefore, this deep divergence event very probably took place in the Triassic, or even in the Permian.

\section{Conclusions}

The abundant data on Pteroliriope sinitshenkovae tax. et sp. nov. allowed us to demonstrate that this species belongs to the Pteronarcyidae, hence the group had already diverged ca. 165 mya. Our studies demonstrate the need for (re-)investigations of the systematics of fossil stoneflies to further refine divergence date estimates for plecopteran lineages. In that endeavour the positive exclusion of fossil species from particular taxa, formalized with combinations such as 'Pteroliriope nec Pteronarcys sinitshenkovae', will be a useful methodological improvement.

\section{Methods}

\section{Wing venation homologies, and abbreviations}

We follow the serial insect wing venation groundplan $[34,35])$, and homologies proposed by Béthoux (2005, [21]) regarding Plecoptera wing venation. The corresponding wing venation nomenclature is repeated for convenience: ScP, posterior Subcosta; RA, anterior Radius; RP, posterior Radius; M, Media; MA, anterior Media; MP, posterior Media; $\mathrm{Cu}$, Cubitus; $\mathrm{CuA}$, anterior Cubitus; $\mathrm{CuP}$, posterior Cubitus; $\mathrm{AA}$ : anterior Analis; AA1: first anterior Analis; AA2, second anterior Analis. The strong and oblique cross-vein occurring between $\mathrm{M}$ and $\mathrm{CuA}$ near the wing base is referred to as the 'arculus'. Stoneflies commonly possess additional specialized cross-veins. They are usually referred to according to the veins they connect. For example, the rp-ma cross-vein connects RP and MA (and see [6]). For figures, right and left forewings are indicated as RFW and LFW respectively, and right and left hind wings as RHW and LHW, respectively. Folds are indicated as ' $\mathrm{f}$ ' when necessary. 
Terminologies and abbreviations for postabdominal elements follow a previous contribution [14]: ahl, anterior hemitergal lobe; mhl, median hemitergal lobe; mhp, mesal hemitergal lobe; phl, posterior hemitergal lobe; ip, inner part of supra-anal process; lb, lateral brace; pgp, paragenital plate; sbl, sub-anal lobe; abs, apical region of dorsal section of supra-anal process; sa, supra-anal process; vp, vaginal projections.

\section{Fossil material}

The fossil material is deposited in the Capital Normal University (CNU; Dong Ren, Curator), was examined using a Leica MZ12.5 or a Zeiss SteREO Discovery V8 dissecting microscope and illustrated with the aid of a drawing tube, under dry and ethanol conditions. The resulting draft drawings were complemented during the inking process (itself performed using Adobe Illustrator CC).

\section{Extant material}

Specimens belonging to Pteronarcella badia (Hagen, 1874) were prepared to complement available data on the wing venation of this species. Specimens were collected (11.vi.2010, Colorado) and determined by BK. Wings were cut off and mounted in white Euparal medium (Asco Laboratories, Manchester, UK). Specimens are deposited at the Entomology Laboratory of Muséum National d'Histoire Naturelle, Paris (France). Specimen numbers are as follows: MNHN.EP654 - MNHN.EP662.

Cladotypes and paracladotypes (belonging to californica Newport, 1851 and princeps Banks, 1907) were collected and determined by BK (2.vi.2010, Colorado; 23.v.2007, California; respectively). Specimens are deposited at the Entomology Laboratory of Muséum National d'Histoire Naturelle, Paris (France).

\section{Photographs}

Photographs were taken using a digital camera Canon EOS 550D or EOS 5D Mark III, coupled to a Canon $50 \mathrm{~mm}$ macro lens, or to a MP-E $65 \mathrm{~mm}$ macro lens, both equipped with polarizing filters. Resulting photographs were optimized using Adobe Photoshop CS6. Unless specified, reproduced photographs of fossil specimens are dry-ethanol composites.

\section{Nomenclature}

We use both the traditional, Linnaean nomenclatural procedure, governed by the International Code of Zoological Nomenclature [36]), and the cladotypic one $([6,23,37,38]$ for taxa; $[39,40]$ for species). The traditional approach was used to warrant the validity of the newly described species. The cladotypic approach was used for its assumed higher optimality [23].

\section{Character states distribution}

We refrained from engaging in a formal, cladistics analysis because important data on several fossil and extant Plecoptera remain to be published. Yet, in order to assess the systematic affinities of the new species, we mapped morphological character states onto a phylogenetic backbone (Fig. 8). The phylogenetic backbone is derived from a former analysis [32] complemented by data from further publications [1, 41]. Morphological data was obtained from several contributions (mainly $[1,3,13,14,21,25-27])$. As for Diamphipnoidae, a very peculiar family of Antarctoperlaria, we relied on Illies (1960; [42]) and on new, unpublished data.

\section{Acknowledgements}

We thank Kevin Arbuckle, an anonymous reviewer and the editorial board of the journal for constructive comments. This work was supported by the German Academic Exchange Service (DAAD; stay of the first author in Germany from April 2013 to April 2014); this work was supported by a grant from Agence Nationale de la Recherche under the LabEx ANR-10-LABX-0003BCDiv, in the program "Investissements d'avenir" n ANR-11-IDEX-0004-02; this work was supported by the National Natural Science Foundation of China (No. 31230065, 41272006, 31672323), Program for Changjiang Scholars and Innovative Research Team in University (IRT13081).

\section{Availability of data and materials}

The fossil material is deposited in the Capital Normal University (CNU, China; Dong Ren, Curator), extant specimens are deposited at the Entomology Laboratory of Muséum National d'Histoire Naturelle, Paris (France).

\section{Authors' contributions}

BK collected and determined extant material; $\mathrm{OB}$ and YC prepared and documented it. YC, CS and DR assembled the fossil material; YC documented it. YC, OB, BK, CS and DR drafted the manuscript. All authors read and approved the final manuscript.

\section{Competing interests}

The authors declare that they have no competing interests (political, personal, religious, ideological, academic, intellectual, commercial or any other), nor are there competing interests in the manuscript.

\section{Consent for publication}

Not applicable.

Ethics approval and consent to participate Not applicable.

\section{Author details}

'Sorbonne Universités, UPMC Univ Paris 06, MNHN, CNRS, Centre de recherche sur la paléobiodiversité et les paléoenvironnements (CR2P), Paris, France. ${ }^{2}$ College of Life Sciences, Capital Normal University, Beijing 100048 , China. ${ }^{3}$ Department of Bioagricultural Sciences and Pest Management, Colorado State University, Fort Collins, CO 80523, USA. ${ }^{4}$ Department of Paleobiology, National Museum of Natural History, Smithsonian Institution, Washington, DC 20013-7012, USA.

Received: 13 May 2016 Accepted: 4 October 2016

Published online: 18 October 2016

References

1. Béthoux O, Cui Y, Kondratieff B, Stark B, Ren D. At last, a Pennsylvanian stem-stonefly (Plecoptera) discovered. BMC Evol Biol. 2011;2011:248.

2. Grimaldi D, Engel MS. Evolution of the insects. New York: Cambridge University Press; 2005

3. Cui Y, Béthoux O, Kondratieff B, Liu Y, Ren D. Sinosharaperla zhaoi (Insecta: Plecoptera; Early (retaceous), a Gondwanian element in the northern hemisphere, or just a misplaced species? J Syst Pal. 2015;13:883-9. 
4. Sinitshenkova ND, et al. Order Perlida Latreille, 1810. The Stoneflies (= Plecoptera Burmeister, 1839). In: History of insects. Dordrecht: Kluwer Academic Publishers; 2002. p. 281-7.

5. Ansorge J. Dobbertiniopteryx capniomimus gen. et sp. nov.-die erste Steinfliege (Insecta: Plecoptera) aus dem Europäischen Jura. Pal Zeit. 1993;67:287-92.

6. Béthoux $\mathrm{O}$, Kondratieff B, Grímsson F, Ólafsson E, Wappler T. Character-statebased taxa erected to accommodate fossil and extant needle stoneflies (Leuctridae - Leuctrida tax.n.) and close relatives. Syst Ent. 2015;40:322-41.

7. Liu Y, Ren D, Sinitshenkova ND, Shih C. The oldest known record of Taeniopterygidae in the Middle Jurassic of Daohugou, Inner Mongolia, China (Insecta: Plecoptera). Zootaxa. 2007;1521:1-8.

8. Liu Y, Sinitshenkova ND, Ren D, Shih C. Pronemouridae fam. nov. (Insecta: Plecoptera), the stem group of Nemouridae and Notonemouridae, from the Middle Jurassic of Inner Mongolia, China. Palaeontology. 2011;54:923-33.

9. Sinitshenkova ND. Istoritcheskoe rasvitie vesnjanok. Tr Pal Inst Aka SSSR. 1987:221:1-143.

10. Newman E. Entomological notes: Perlites. Ent Mag. 1838;5:175-8.

11. Banks N. New genera and species of Nearctic neuropteroid insects. Trans Am Ent Soc. 1900;26:239-59.

12. Hagen HA. Report on the pseudo-Neuroptera and Neuroptera collected by Lieut. W. J. Carpenter in 1873 in Colorado. In: Hayden FV, editor. Annual report of the United States geological and geographical survey of the territories, embracing Colorado, being a report of progress of the exploration of the years 1873, vol. 7. Washington DC: Government Printing Office; 1874. p. 571-606.

13. Needham JG, Claassen PW. A monograph of the Plecoptera or Stoneflies of America North of Mexico. LaFayette: Thomas Say Foundation; 1925.

14. Nelson $\mathrm{CH}$, Hanson JF. Contribution to the anatomy and phylogeny of the family Pteronarcidae [sic] (Plecoptera). Trans Am Ent Soc. 1971;97:123-200.

15. Newport G. On the anatomy and affinities of Pteronarcys regalis, Newm. with a postscript containing descriptions of some American Perlidae, together with notes on their habits. Trans Linn Soc London. 1851;20:425-51.

16. Banks N. A list of Perlidae from British Columbia and Alberta. Can Entomol. 1907;39:323-30.

17. DeWalt RE, Maehr MD, Neu-Becker U, Stueber G. Plecoptera species file online. Version 5.0/5.0. In: Book Plecoptera species file online. Version 5.0/5. 0. (Editor ed.^eds.). City; 2013.

18. Huang D, Nel A, Shen Y, Selden PA, Lin Q. Discussions on the age of the Daohugou fauna - evidence from invertebrates. Progress Nat Sci. 2006;16:309-12.

19. Gao K, Ren D. Radiometric dating of ignimbrite from Inner Mongolia provides no indication of a post-Middle Jurassic age for the Daohugou beds. Acta Geol Sinica. 2006:80:42-5.

20. Liu Y, Liu Y, Ji S, Yang Z. U-Pb zircon age for the Daohugou Biota at Ningcheng of Inner Mongolia and comments on related issues. Chin SC Bull. 2006:51:2634-44.

21. Béthoux O. Wing venation pattern of Plecoptera (Neoptera). Illiesia. 2005;1:52-81.

22. Béthoux O, Gu J, Yue Y, Ren D. Miamia maimai n. sp., a new Pennsylvanian stem-orthopteran insect, and a case study on the application of cladotypic nomenclature. Fossil Record. 2012;15:103-13.

23. Béthoux O. Optimality of phylogenetic nomenclatural procedures. Org Div Evol. 2010;10:173-91.

24. Liu Y, Sinitshenkova ND, Ren D. A new genus and species of stonefly (Insecta: Plecoptera) from the Yixian Formation, Liaoning Province, China. Cret Res. 2007:28:322-6.

25. Uchida S, Isobe Y. Styloperlidae, stat. nov. and Microperlinae, subfam. nov. with a revised system of the family group Systellognatha. Spixiana. 1989;12:145-82.

26. Stewart KW, Stark BP. Plecoptera. In: Merritt RW, Cummins KW, Berg MB, editors. An introduction to the aquatic insects of North America. 4th ed. Dubuque: Kendall Hunt; 2008. p. 311-84.

27. Stewart KW, Harper PP. Plecoptera. In: Merritt RW, Cummins KW, editors. An introduction to the aquatic insects of North America. 3rd ed. Dubuque: Kendall Hunt; 1996. p. 217-66.

28. Cui Y, Béthoux O, Klass K-D, Ren D. The Jurassic Bajanzhargalanidae (Insecta: Grylloblattida?): new genera and species, and data on postabdominal morphology. Arth Struct Dev. 2015;44:688-716.
29. Burmeister HCC. Handbuch der Entomologie. Zweiter Band. Besondere Entomologie. Zweite Abtheilung. Kaukerfe Gymnognatha. (Zweite Hälfte. vulgo Neuroptera). Berlin: Enslin; 1839.

30. Liu Y, Sinitshenkova ND, Ren D. A revision of the Jurassic stonefly genera Dobbertiniopteryx Ansorge and Karanemoura Sinitshenkova (Insecta: Plecoptera), with the description of new species from the Daohugou locality, China. Pal J. 2009;43:183-90.

31. Sinitshenkova ND. New stoneflies (Insecta: Perlida = Plecoptera) from the Late Mesozoic locality Khasurty, Transbaikalia. Pal J. 2011:45:552-8.

32. Zwick P. Phylogenetic system and zoogeography of the Plecoptera. Ann Rev Entomol. 2000;45:709-46.

33. Misof B, Liu S, Meusemann K, Peters RS, Donath A, Mayer C, Frandsen PB, Ware J, Flouri T, Beutel RG, et al. Phylogenomics resolves the timing and pattern of insect evolution. Science. 2014;346:763-7.

34. Lameere A. Sur la nervation alaire des insectes. Bull Cl Sc Acad Roy Belg. 1922;8:138-49.

35. Lameere A. On the wing-venation of insects. Psyche. 1923;30:123-32.

36. ICZN. International code of zoological nomenclature. 4th ed. London: The International Trust for Zoological Nomenclature; 1999.

37. Béthoux O. Propositions for a character-state-based biological taxonomy. Zool Scr. 2007;36:409-16.

38. Béthoux O. Cladotypic taxonomy revisited. Arth Syst Phyl. 2007:65:127-33.

39. Lanham U. Uninominal nomenclature. Syst Zool. 1965;14:144.

40. Dayrat B, Schander C, Angielczyk K. Suggestions for a new species nomenclature. Taxon. 2004;53:485-91.

41. McCulloch GA, Wallis GP, Waters JM. A time-calibrated phylogeny of southern hemisphere stoneflies: Testing for Gondwanan origins. Mol Phyl Evol. 2016;96:150-60.

42. Illies J. Archiperlaria, eine neue Unterordnung der Plecopteren (Revision der Familien Eustheniidae und Diamphipnoidae) (Plecoptera). Beitr Ent. 1960;10:661-97.

\section{Submit your next manuscript to BioMed Central and we will help you at every step:}

- We accept pre-submission inquiries

- Our selector tool helps you to find the most relevant journal

- We provide round the clock customer support

- Convenient online submission

- Thorough peer review

- Inclusion in PubMed and all major indexing services

- Maximum visibility for your research

Submit your manuscript at www.biomedcentral.com/submit 